\title{
CORRECTION
}

\section{Correction to: Decision support tools for wind and solar farm site selection in Isfahan Province, Iran}

\author{
Mojtaba Barzehkar ${ }^{1}[$ ( $)$ Kevin E. Parnell ${ }^{1,2} \cdot$ Naghmeh Mobarghaee Dinan $^{3} \cdot$ Graham Brodie $^{4}$
}

Published online: 24 December 2020

๑) Springer-Verlag GmbH Germany, part of Springer Nature 2020

\section{Correction to: Clean Technologies and Environmental Policy https://doi.org/10.1007/s10098-020-01978-w}

In the original publication, the Figs. 4 and 5 were swapped mistakenly. The correct figures with their caption are provided in this correction.

The original article has been corrected.

The original article can be found online at https://doi.org/10.1007/ s10098-020-01978-w.

Mojtaba Barzehkar mojtaba.barzehkar@taltech.ee

1 Department of Cybernetics, School of Science, Tallinn University of Technology, Tallinn, Estonia

2 College of Science and Engineering, James Cook University, Townsville, Australia

3 Environmental Sciences Research Institute, Shahid Beheshti University, Tehran, Iran

4 Faculty of Agricultural Sciences, Melbourne University, Melbourne, Australia 


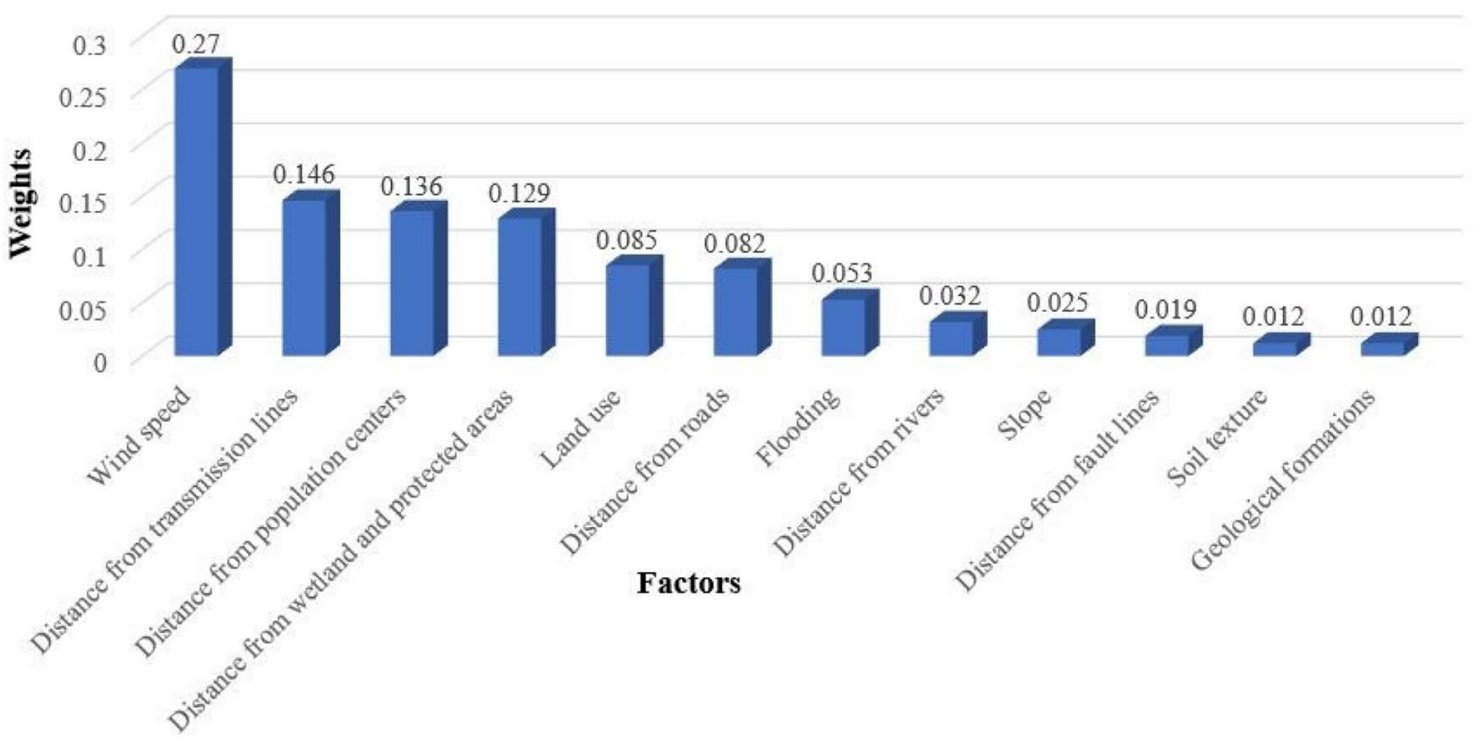

Fig. 4 Final weights and priorities assigned to the environmental and socioeconomic factors for wind farm site selection

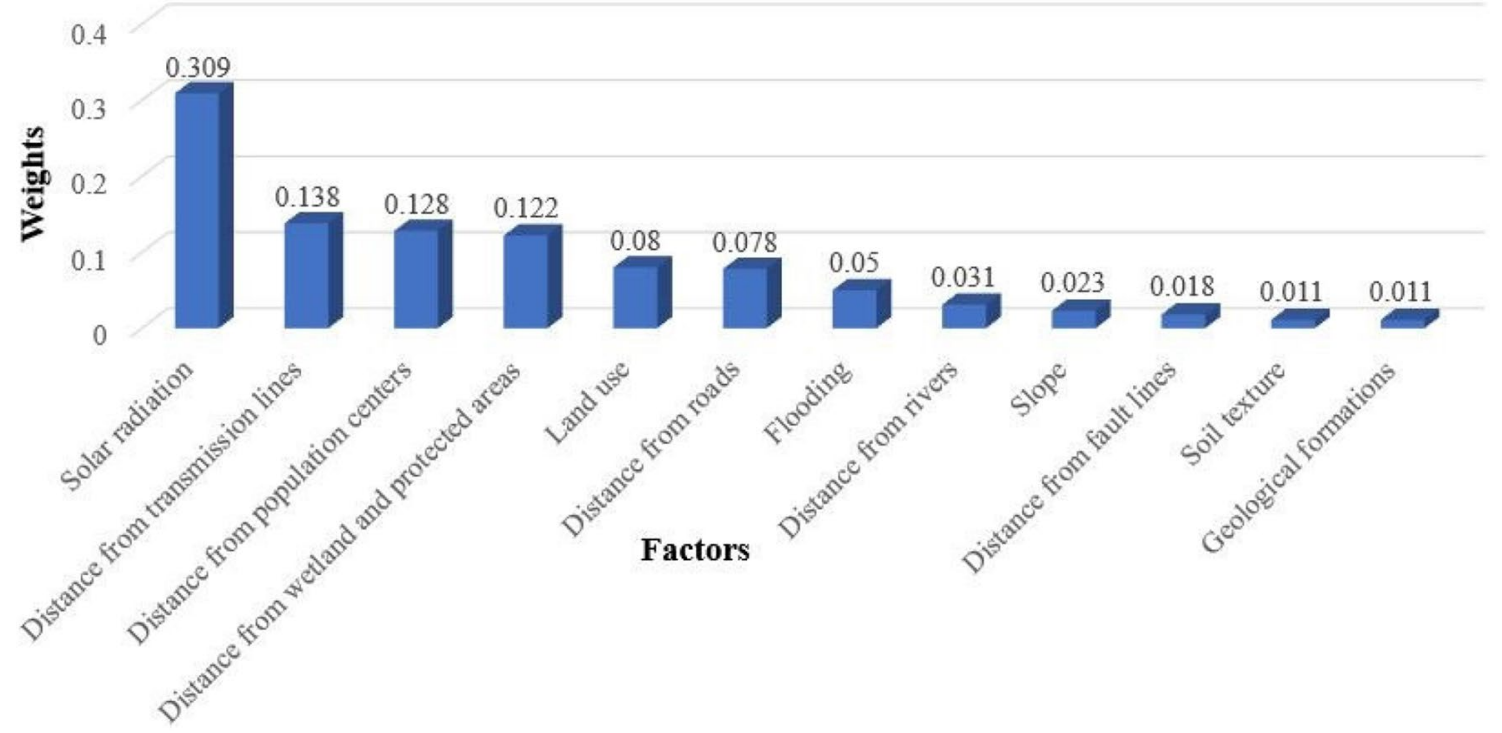

Fig. 5 Final weights and priorities assigned to the environmental and socioeconomic factors for solar farm site selection

Publisher's Note Springer Nature remains neutral with regard to jurisdictional claims in published maps and institutional affiliations. 